\title{
Outcomes of Shoulder Functions in Spinal Accessory to Suprascapular Nerve Transfer in Brachial Plexus Injury: A Comparison between Anterior and Posterior Approach
}

\author{
Sanjay Maurya ${ }^{1}$ Gopi Renganathan ${ }^{1}$ Venkatnarayanan R. ${ }^{1} \quad$ Rajiv Bharti ${ }^{1}$ \\ ${ }^{1}$ Department of Plastic Surgery, AFMC, Pune, Maharashtra, India \\ Address for correspondence Sanjay Maurya, M.Ch, Department \\ of Plastic Surgery, AFMC Pune, Maharashtra, 411040, India \\ (e-mail: drsanjaykmaurya@gmail.com).
}

Indian J Plast Surg 2021;54:152-156.

\begin{abstract}
Keywords

- nerve transfer

- brachial plexus injury

- posterior approach

- suprascapular nerve

- spinal accessory nerve

Background Restoration of shoulder functions is important in brachial plexus injury (BPI). The functional outcomes of spinal accessory nerve (SAN) to suprascapular nerve (SSN) transfer by the anterior supraclavicular approach and the posterior approach is a matter of debate. This article aims to compare the outcomes of the shoulder functions by the SAN to the SSN transfer using the two approaches.

Methods Retrospective data was collected in 34 patients who underwent SAN to SSN transfer from January 2016 to June 2018. Group A included 16 patients who underwent nerve transfers by anterior approach, and Group B included 18 patients who underwent nerve transfers by posterior approach. Functional outcomes were measured by grading the muscle power as per the British Medical Research Council (MRC) grading (graded as $\mathrm{M}$ ) and the range of motions (ROM) of the shoulder at 6 months and 18 months.

Results Early recovery was seen in group B with 7 patients (39\%) showing $\mathrm{M} 1$ abduction power at 6 months as compared with one patient (6\%) in group $\mathrm{A}$. This difference was statistically significant $(p$ value $=0.04$ ). At 18 months, 10 patients $(62 \%)$ in group A had good recovery (MRC grade $\geq 3$ ), while 13 patients ( $72 \%$ ) in group B had a good recovery. This difference was not found to be statistically significant (Fisher exact test $p$ value $=0.71$ ) There was no statistical difference in the outcomes of ROM in shoulder abduction, external rotation, and motor power at 18 months of follow-up. Conclusions Early recovery was observed in the posterior approach group at 6 months, however, there was no significant difference in the outcomes of shoulder functions in muscle power and ROM in the two groups at 18 months of follow-up.
\end{abstract}

\section{Introduction}

Reconstruction of brachial plexus injury (BPI) is challenging, and patients with BPI restoration of elbow functions, ${ }^{1}$ followed

published online June 28, 2021

$10.1055 / \mathrm{s}-0041-1731255$
DOI https://doi.org/

ISSN 0970-0358 by shoulder functions, are given priority. The shoulder functions have traditionally been restored by the spinal accessory nerve (SAN) to suprascapular nerve (SSN) transfer in an irreparable root avulsion in BPI. The anterior approach by (c) 2021. Association of Plastic Surgeons of India.

This is an open access article published by Thieme under the terms of the Creative Commons Attribution-NonDerivative-NonCommercial-License, permitting copying and reproduction so long as the original work is given appropriate credit. Contents may not be used for commercial purposes, or adapted, remixed, transformed or built upon. (https://creativecommons.org/licenses/by-nc-nd/4.0/).

Thieme Medical and Scientific Publishers Pvt. Ltd. A-12, 2nd Floor, Sector 2, Noida-201301 UP, India 
a supraclavicular incision has been widely practiced by the brachial plexus surgeons while performing this nerve transfer. This approach can lead to denervation of a part of the trapezius muscle, which plays an important role in shoulder stability. ${ }^{2}$ The posterior approach described by Guan et $\mathrm{al}^{3}$ is advantageous, as the neurotization is close to the target muscle and can be performed in the presence of previous suprascapular scars and suspected distal injury to the SSN as in scapula fractures. There are few studies which compare the outcomes of shoulder functions using the anterior and the posterior approach. This study aims to compare the outcomes of shoulder functions following SAN to SSN transfer using the anterior and posterior approaches.

\section{Materials and Methods}

All adult patients with BPI from January 2016 to June 2018 who were operated were included in the study. Retrospective data was collected from the brachial plexus registry and collated. With the available data, two groups were identified: group A- SAN to SSN transfer using the anterior approach and group B- SAN to SSN by the posterior approach. The inclusion criteria were as follows: 1 . unrecovered adult posttraumatic BPI presenting between 3 to 9 months after injury; 2. clinical and radiological evidence of root avulsion injury or irreparable root injury; 3 . no secondary reconstruction to restore shoulder functions; 4 . follow-up for 18 months. Depending upon the extent of the lesion, the injury was classified into partial (C5,6, or C5-7) or total (C5-T1 injury). Demographic data like age, gender, mechanism of injury, time to surgery, and dominance of the extremity were also recorded. The clinical examination was done to assess the range of motion (ROM) using a goniometer. The shoulder abduction was measured posteriorly with the patient standing and the angle formed between the axis of the arm and the lateral thoracic wall. The external rotation was measured with the arm fully adducted, internally rotated, and elbow flexed at 90 degrees with the forearm placed over the chest. The motor power was recorded using British Medical Research Council (MRC) grading. The trapezius muscle power was measured preoperatively and at 18 months postoperatively. The follow-up data of shoulder abduction at 6,12 , and 18 months was recorded. For the comparison between the groups, the final assessment was done at 18 months. The muscle power of MRC grade 3 and above was classified as a good recovery and MRC grade 2 and below was classified as poor. The MRI findings and electrophysiological studies were also tabulated; however, these were not used for the operative decision-making, as this was based on clinical findings. The reconstructive plan followed in all cases was:

1. SAN to SSN transfer for shoulder abduction.

2. Long head triceps branch of the radial nerve to the anterior branch of axillary nerve for deltoid reanimation (in C5-6 root avulsions).

3. Oberlin transfer for elbow flexion (In C5-7 root avulsion).

4. 3rd, 4th, 5th intercostal nerves (ICN) to musculocutaneous nerve (MCN) for elbow flexion in total BPI.

\section{Surgical Technique}

Patients were placed in the supine position, and anterior exploration of the brachial plexus was done to reconstruct the brachial plexus. In group A, SAN to SSN was done along with the other nerve transfers as per the reconstructive plan. In group $\mathrm{B}$, the brachial plexus was explored in the supine position and the wound was temporarily closed. Patients were then turned into the prone position and SAN to SSN was transferred. The long head triceps branch of the radial nerve to the anterior branch of the axillary nerve for deltoid reanimation (in C5-6 root avulsions) was also done in the same position. The patients were again placed the supine and other nerve transfers were done as per the reconstructive plan.

\section{The Anterior Approach}

The patient was placed the supine with a head supported by a head ring and turned to the opposite side. The exploration of brachial plexus and the transfer of SAN to SSN was performed by the technique as previously described. ${ }^{4}$ Nerve coaptation was done with 9-0 nylon and fibrin glue. The arm was immobilized for 3 weeks with adhesive plaster and the forearm across the chest. A gradual passive ROM was initiated after 3 weeks.

\section{The Posterior Approach}

The patient was placed in the prone position and surface anatomy of the nerves was marked ( - Fig. 1). SAN to SSN transfer was done as per the technique described by

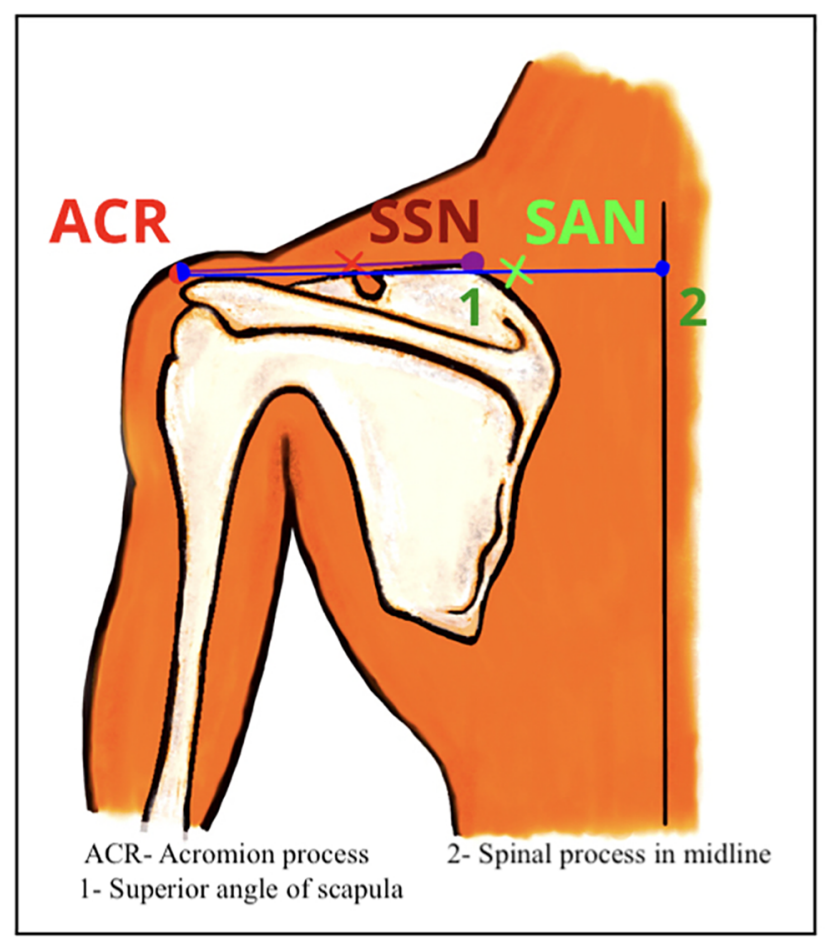

Fig. 1 Preoperative markings for posterior approach (the midline spinous process is marked (point 2) and the acromion as ACR. The spinal accessory nerve (SAN) is located at a distance $40 \%$ from the dorsal midline to the ACR. The superior angle of the scapula is marked (point 1) and suprascapular nerve (SSN) is located at midpoint between ACR and superior angle of scapula. 
Colbert et al. ${ }^{5}$ The SSN nerve was transected as far proximally as possible, and SAN was divided distally for a tension free coaptation with 9-0 nylon and fibrin glue (- Figs 2-3). Immobilization and postoperative exercises were similar to the anterior approach.

\section{Statistical Analysis}

The data were tabulated in Microsoft Excel (Microsoft Corporation, USA), and statistical analysis was performed using SPSS software version 20 (SPSS Inc. Chicago). The paired $t$-test was used to compare the difference between the means, and Fisher exact test was used to test the difference between the proportions. In all the parameters, a $p$ value of $<0.05$ was considered statistically significant.

\section{Results}

A total of 34 patients were included in the study with 16 in group A and 18 in group B. All patients were male, and all were involved in a road traffic accident (RTA) with a motorcycle except one in group A, who sustained an injury due to a fall from height. The demographic data, time to surgery, the extent of injury, and the extremity dominance are shown in - Table 1. Shoulder examination of all cases revealed wasting of supraspinatus, infraspinatus, and deltoid with glenohumeral subluxation. The most common MRI findings were of pseudomeningoceles with severe scarring of roots in 13 patients in group $A$ and 14 patients in group B. All patients

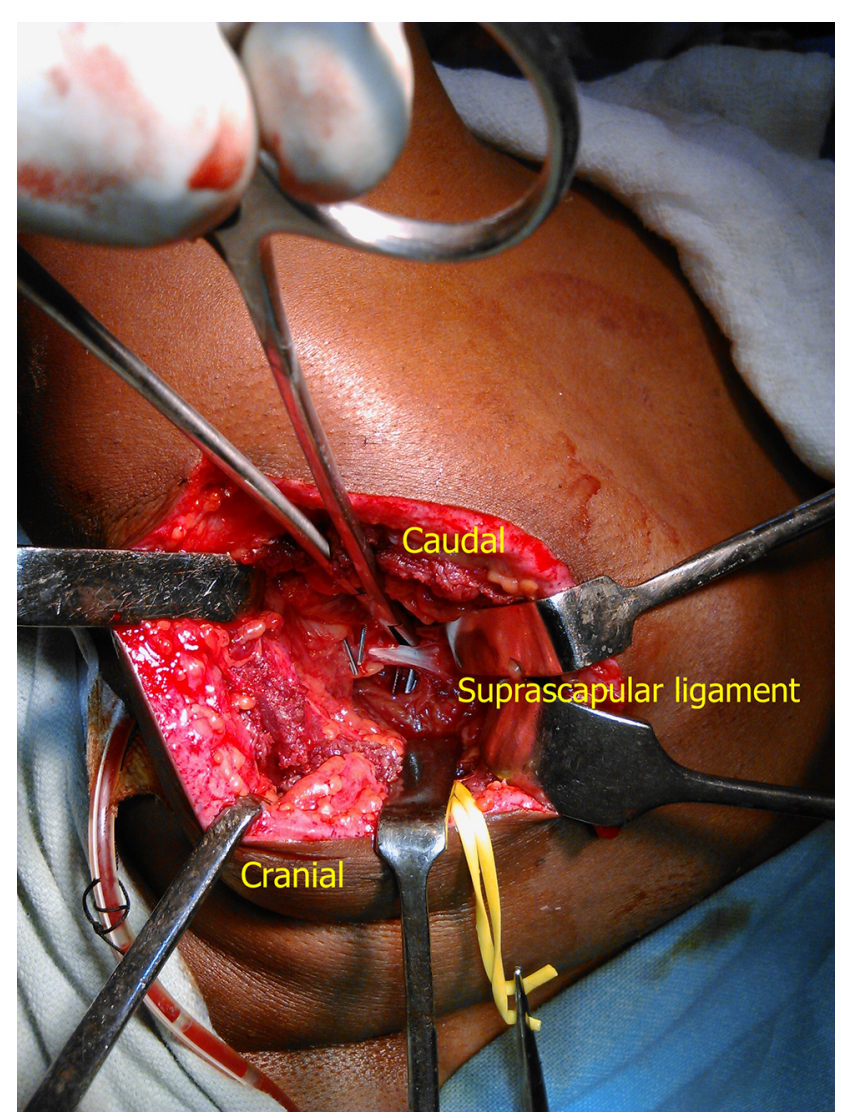

Fig. 2 Transverse suprascapular ligament.

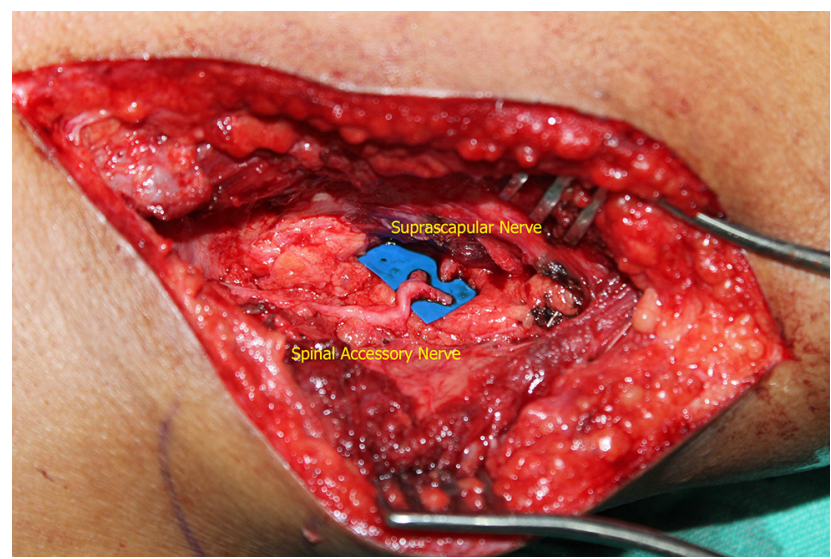

Fig. 3 Nerve transfer spinal accessory nerve (SAN) to suprascapular nerve (SSN).

in both groups showed features of chronic denervation with no features of reinnervation in the electrophysiological studies. In three cases of group A, clavicle fracture was well united without scarring. However, of the 3 cases of clavicle fracture in group $B$, one presented after clavicle fixation and the other two had malunited fracture with significant callus formation. One case had posttraumatic scars in the supraclavicular fossa in group B. In these four cases, we could not explore the brachial plexus due to scarring in the supraclavicular fossa. At postoperative 6 months, M1 shoulder abduction was noted in one patient in group A versus six in group B. This difference was found to be statistically significant. At 18 months in group A, two patients had M4 power, while in group B, five patients had M4 power. The mean shoulder abduction at 18 months was $51.42^{\circ}$ versus $57.22^{\circ}$ in groups $A$ and $B$, respectively. The differences in the MRC grade and ROM was not found to be statistically significant (

There was no active external rotation shoulder observed in both the groups at 6 months (M0). At 18 months, no patient had M4 recovery in group A versus one in group B ( - Table 2 ). No statistical difference in external rotation was noted in two groups $\left(13.75^{\circ}\right.$ vs. $\left.21.39^{\circ}\right)$ at 18 months. Ten patients in group A and 13 patients in group B had a good recovery at 18 months (-Table 2). There was no significant difference in the outcomes in the two groups in cases of partial and total injury. However, the outcomes of partial injuries were better than total BPI in both the groups (- Table 2). There was no loss of power in trapezius in both the groups. We did not encounter any distal injuries in the cohort studied.

\section{Discussion}

Shoulder stability and its functions are important for upper extremity rehabilitation in BPI. Primary nerve surgery has superior functional outcomes, as it restores functions more physiologically. Distal nerve transfer has improved the outcomes of shoulder functions in irreparable root injury and also in patients with delayed presentation. The outcomes of shoulder functions are determined by several factors, which include the extent of the injury and the number of nerve transfers performed. The results of nerve transfers in upper 
Table 1 Demographic data

\begin{tabular}{|l|l|l|l|}
\hline & Anterior $(\boldsymbol{n}=\mathbf{1 6})$ & Posterior $(\boldsymbol{n}=\mathbf{1 8})$ & $\boldsymbol{p}$ value \\
\hline Age & $32.06 \pm 12.87$ & $32.5 \pm 12.94$ & 0.46 \\
\hline Time to surgery & $6.38 \pm 2.0$ & $6.50 \pm 2.32$ & 0.43 \\
\hline Partial injury & 9 & 11 & 1 \\
\hline Total injury & 7 & 7 & - \\
\hline Dominant upper limb & 9 & 11 & - \\
\hline Fracture clavicle & 3 & 3 & \\
\hline
\end{tabular}

Table 2 Outcomes of shoulder functions at 18 months

\begin{tabular}{|c|c|c|c|c|c|c|c|c|c|c|c|c|c|c|c|}
\hline \multirow[t]{2}{*}{ Approach } & \multicolumn{5}{|c|}{ MRC grade } & \multirow[t]{2}{*}{$\begin{array}{l}p \\
\text { value }\end{array}$} & \multirow[t]{2}{*}{$\begin{array}{l}\text { ROM } \\
\text { (degrees) }\end{array}$} & \multirow[t]{2}{*}{$\begin{array}{l}p \\
\text { value }\end{array}$} & \multicolumn{2}{|c|}{$\begin{array}{c}\text { Final } \\
\text { outcome }\end{array}$} & \multirow[t]{2}{*}{$\begin{array}{l}p \\
\text { value }\end{array}$} & & & & \\
\hline & M4 & M3 & M2 & M1 & M0 & & & & Good & Poor & & $\begin{array}{l}\text { Partial } \\
\text { injuries } \\
\text { (ROM) }\end{array}$ & $\begin{array}{l}p \\
\text { value }\end{array}$ & $\begin{array}{l}\text { Total } \\
\text { injuries } \\
\text { (ROM) }\end{array}$ & $p$ value \\
\hline & \multicolumn{6}{|c|}{ Abduction(n) } & \multicolumn{2}{|c|}{ Abduction } & \multicolumn{3}{|c|}{ Abduction(n) } & \multicolumn{4}{|c|}{ Abduction } \\
\hline Anterior & 2 & 8 & 6 & - & - & \multirow[t]{2}{*}{0.51} & $\begin{array}{l}51.42 \pm \\
28.51\end{array}$ & \multirow[t]{2}{*}{0.37} & 10 & 6 & \multirow[t]{2}{*}{0.71} & $\begin{array}{l}71.10 \pm \\
16.60\end{array}$ & \multirow[t]{2}{*}{0.46} & $\begin{array}{l}25.70 \pm \\
18.13\end{array}$ & 0.78 \\
\hline \multirow[t]{2}{*}{ Posterior } & 5 & 8 & 4 & 1 & - & & $\begin{array}{l}57.22 \pm \\
49.44\end{array}$ & & 13 & 5 & & $\begin{array}{l}76.82 \pm \\
51.20\end{array}$ & & $\begin{array}{l}26.43 \pm \\
27.03\end{array}$ & \\
\hline & \multicolumn{6}{|c|}{ External rotation(n) } & \multicolumn{2}{|c|}{ External rotation } & \multicolumn{3}{|c|}{ External rotation $(n)$} & \multicolumn{4}{|c|}{ External rotation } \\
\hline Anterior & - & 3 & 9 & 2 & 2 & \multirow[t]{2}{*}{0.52} & $\begin{array}{l}13.75 \pm \\
14.08\end{array}$ & \multirow[t]{2}{*}{0.35} & 3 & 13 & \multirow[t]{2}{*}{0.46} & $\begin{array}{l}22.20 \pm \\
13.07\end{array}$ & \multirow[t]{2}{*}{0.35} & $\begin{array}{l}2.9 \pm \\
4.80\end{array}$ & \multirow[t]{2}{*}{0.14} \\
\hline Posterior & 1 & 5 & 6 & 5 & 1 & & $\begin{array}{l}21.39 \pm \\
28.01\end{array}$ & & 6 & 12 & & $\begin{array}{l}32.73 \pm \\
30.90\end{array}$ & & $\begin{array}{l}3.57 \pm- \\
4.75\end{array}$ & \\
\hline
\end{tabular}

Abbreviations: Medical Research Council. MRC; ROM, range of motion.

BPI are better than those seen in total palsy. ${ }^{6}$ The SAN to SSN transfer provides stability to the shoulder and improves shoulder abduction and external rotation ${ }^{7,8}$ The stability of the shoulder along with abduction has been reported to have been achieved in 60 to $80 \%$ of all cases undergoing this nerve transfer, ${ }^{9}$ which can be done by an anterior or posterior approach.

The advantages of the anterior approach include ease of patient positioning, a simultaneous exploration of brachial plexus, repair and reconstruction in case of rupture of brachial plexus roots, and a higher proportion of axons from SAN available for transfer. However, this approach may not be feasible in a scarred supraclavicular region either due to previous surgery or injury in that region. ${ }^{10}$ The advantages of posterior approaches include preservation of functions of the upper part of trapezius ${ }^{11}$ and nerve transfer closed to the target muscle. This approach is also advantageous in cases of suspected injury to SSN at multiple levels. ${ }^{12,13}$ However, we did not find any distal injuries or injuries at multiple levels, which may be attributed to the small sample size. The disadvantages include change of position from supine to prone, large incisions at the back along with detachment of the trapezius muscle from its scapular spine attachment. Besides, reduced axonal counts on the distal part of SAN may also be of a disadvantage. ${ }^{14}$ The outcomes of the posterior approach in SAN to SSN transfer have been variable, with many authors reporting better outcomes as compared with anterior approach. ${ }^{15,16}$
In this study, 18 patients who underwent SAN to SSN transfer, a statistically significant early clinical recovery of shoulder abduction was seen in group $\mathrm{B}$. Bhandari et $\mathrm{al}^{15}$ in their study of 14 cases of BPI managed with SAN to SSN transfer by dorsal approach, with initial evidence of shoulder abduction being achieved at $28 \pm 4$ weeks as compared with $34 \pm 4$ weeks by anterior approach. The early recovery in the posterior approach can be attributed to the nerve transfer close to the target muscle, thereby reducing the reinnervation time.

While comparing the MRC grade and ROM of shoulder abduction at 18 months, it appeared group B fared better in terms of absolute numbers, however, there was no statistical significant difference in the two groups, which is consistent with other published studies. ${ }^{17,18}$ However, Bhandari et al and ${ }^{15}$ Guan et $a{ }^{16}$ found better outcomes of shoulder abduction by the posterior approach. In both the studies, the authors compared the results of the posterior approach in patients who were operated earlier by anterior approach which might have influenced the outcomes.

Similar to our study, the results of external rotation have been reported to be inferior as compared with shoulder abduction by SAN to SSN transfer. ${ }^{19,20}$ In group B, 5 (27.7\%) patients had an external rotation of MRC grade $\geq 3$ as compared with 3 (18.75\%) patients in group A. There was no significant difference in ROM of the external rotation between the two groups. However, Souza et $\mathrm{al}^{17}$ found superior outcomes in external rotation with a posterior approach but 
did not find any difference in the outcomes of shoulder abduction. This could be due to the results that authors have reported in partial BPI involving C5-6 roots only.

There are wide variations in the outcomes of SAN to SSN transfers in partial and total injuries, which is due to several differential variables. The outcomes of partial and total BPI in group A and B were similar, with no statistically significant difference. However, the partial injuries had superior outcomes in ROM of shoulder abduction $\left(71.10^{\circ}\right.$ \& $76.82^{\circ}$ in group $A \& B$, respectively) as compared with total injury $\left(25.70^{\circ} \& 26.43^{\circ}\right.$ group A \& B, respectively). These findings are inferior to the study published by Bertelli et al ${ }^{6}$ but similar to other studies published by Venkatramani et $\mathrm{al}^{21}$ and Mohammadreza et al. ${ }^{22}$ This is due to the target of the selective muscle innervated by the SSN in a totally flail limb.

Postoperative weakness of trapezius in SAN to SSN transfer by the anterior approach has been reported by some authors. ${ }^{2}$ According to Bhandari et $\mathrm{al},{ }^{15}$ in a control group of 21 patients who underwent SAN to SSN transfer, 18 patients experienced downgrading of MRC grade by 1 and 3 patients by 2 MRC grade. However, we did not notice any weakness of trapezius function at the final follow-up as we tried to preserve as many proximal branches of SAN as possible and dividing the donor nerve as distally as possible.

The study has limitations primarily due to the small sample size and absence of postoperative electrophysiological studies, which would have objectively documented the early recovery. However, due to logistic and financial reasons, we relied on clinical recovery.

\section{Conclusion}

In conclusion, early shoulder abduction was noticed in group B at 6 months, but there was no statistically significant difference in the outcomes at 18 months in both the groups. However, intraoperative change of position and longer operative time may be of disadvantage in the posterior group. Nevertheless, the posterior approach can be useful in a scarred suprascapular region or in patients with suspected distal suprascapular nerve lesions.

\section{Conflicts of Interest}

None declared.

\section{References}

1 Bhatia A, Kulkarni A, Zancolli P, et al. The effect of age and the delay before surgery on the outcomes of intercostal nerve transfers to the musculocutaneous nerve: a retrospective study of 232 cases of posttraumatic total and near-total brachial plexus injuries. Indian J Plast Surg 2020;53(2):260-265

2 Bhandari PS, Maurya S. Recent advances in the management of brachial plexus injuries. Indian J Plast Surg 2014;47(2):191-198

3 Guan SB, Chen DS, Fang YS, et al. An anatomic study of the descending branch of the spinal accessory nerve transfer for the repair of suprascapular nerve to restore the abduction function of the shoulder through the dorsal approach. Chin J Hand Surg(Chin) 2004;20:55-57
4 Bhandari PS, Sadhotra LP, Bhargava P, et al. Surgical outcomes following nerve transfers in upper brachial plexus injuries. Indian J Plast Surg 2009;42(2):150-160

5 Colbert SH, Mackinnon S. Posterior approach for double nerve transfer for restoration of shoulder function in upper brachial plexus palsy. Hand (N Y) 2006;1(2):71-77

6 Bertelli JA, Ghizoni MF. Transfer of the accessory nerve to the suprascapular nerve in brachial plexus reconstruction. J Hand Surg Am 2007;32(7):989-998

7 Merrell GA, Barrie KA, Katz DL, Wolfe SW. Results of nerve transfer techniques for restoration of shoulder and elbow function in the context of a meta-analysis of the English literature. J Hand Surg Am 2001;26(2):303-314

8 Songcharoen P, Wongtrakul S, Spinner RJ. Brachial plexus injuries in the adult. nerve transfers: the Siriraj Hospital experience. Hand Clin 2005;21(1):83-89

9 Terzis JK, Kostas I, Soucacos PN. Restoration of shoulder function with nerve transfers in traumatic brachial plexus palsy patients. Microsurgery 2006;26(4):316-324

10 Leechavengvongs S, Malungpaishorpe K, Uerpairojkit C, Ng CY, Witoonchart K. Nerve transfers to restore shoulder functions. Hand Clin 2016;32(2):153-164

11 Dailiana ZH, Mehdian H, Gilbert A. Surgical anatomy of spinal accessory nerve: is trapezius functional deficit inevitable after division of the nerve? J Hand Surg [Br] 2001;26(2):137-141

12 Ochiai N, Nagano A, Okinaga S, Murashima R, Tachibana S. Brachial plexus injuries: surgical treatment of combined injuries of the axillary and suprascapular nerves. J Jpn Soc Surg Hand 1988;5:151-155

13 Mikami Y, Nagano A, Ochiai N, Yamamoto S. Results of nerve grafting for injuries of the axillary and suprascapular nerves. J Bone Joint Surg Br 1997;79(4):527-531

14 Pruksakorn D, Sananpanich K, Khunamornpong S, Phudhichareonrat S, Chalidapong P. Posterior approach technique for accessory-suprascapular nerve transfer: a cadaveric study of the anatomical landmarks and number of myelinated axons. Clin Anat 2007;20(2):140-143

15 Bhandari PS, Deb P. Dorsal approach in transfer of the distal spinal accessory nerve into the suprascapular nerve: histomorphometric analysis and clinical results in 14 cases of upper brachial plexus injuries. J Hand Surg Am 2011;36(7):1182-1190

16 Guan SB, Hou CL, Chen DS, Gu YD. Restoration of shoulder abduction by transfer of the spinal accessory nerve to suprascapular nerve through dorsal approach: a clinical study. Chin Med J (Engl) 2006;119(9):707-712

17 Souza FH, Bernardino SN, Filho HC, et al. Comparison between the anterior and posterior approach for transfer of the spinal accessory nerve to the suprascapular nerve in late traumatic brachial plexus injuries. Acta Neurochir (Wien) 2014;156(12):2345-2349

18 Rui J, Zhao X, Zhu Y, Gu Y, Lao J. Posterior approach for accessory-suprascapular nerve transfer: an electrophysiological outcomes study. J Hand Surg Eur Vol 2013;38(3):242-247

19 Terzis JK, Kostas I. Suprascapular nerve reconstruction in 118 cases of adult posttraumatic brachial plexus. Plast Reconstr Surg 2006;117(2):613-629

20 Chuang DC, Lee GW, Hashem F, Wei FC. Restoration of shoulder abduction by nerve transfer in avulsed brachial plexus injury: evaluation of 99 patients with various nerve transfers. Plast Reconstr Surg 1995;96(1):122-128

21 Venkatramani H, Bhardwaj P, Faruquee SR, Sabapathy SR. Functional outcome of nerve transfer for restoration of shoulder and elbow function in upper brachial plexus injury. J Brachial Plex Peripher Nerve Inj 2008;3:15

22 Mohammadraza E, Alijani B, Andalib S. Long term clinical outcomes of spinal accessory nerve transfer to suprascapular nerve in patients with brachial plexus injury. Acta Neurochir (Wien) 2016;158(9):1801-1806 